\title{
A brief review of plagiarism in medical scientific research papers
}

\author{
Mohammad Karami*, Gholam Hassan Danaei \\ Department of Toxicology and Pharmacology, Faculty of Pharmacy, Mazandaran University of Medical Sciences, Sari, Iran \\ Received: Jan 13, 2016, Revised: Jun 15, 2016, Accepted: Jul 20, 2016
}

\begin{abstract}
Plagiarism refers to "adopting someone else's words, work or ideas and passing them off as one's own". It is potentially considered as the most prevalent form of scientific dishonesty discovered in research papers. The present review aims to provide a thorough account of plagiarism to build awareness about all dimensions of plagiarism.The key words "plagiarism", "types", "detection" and "consequences" have been applied to retrieve the articles from electronic references such as MEDLINE database.

Around five hundred articles have been retrieved. The articles have been subdivided, each group encompassed a dimension of plagiarism. The major findings and updates have been summarized for each topic. The most important reason behind plagiarism as spotted is lack of knowledge about the subject. And when the researchers are trapped with deficient time, in experienced writing skills and the pressure in order get their work published in some decent journals, the authors surreptitiously take access others work and commit plagiarism. Before, detecting plagiarism used to be difficult; however, in recent years, the journals have devised many plagiarism-detection services and software programs. The current article provides the details on how the journals use these services and software tool to effectively check for plagiarism in submitted manuscripts. In academic settings, plagiarism is a potential devastating offense.

Plagiarism is taken as the most common problem in research writing. The most critical way to curb it is to build up awareness about how to cope with this ever increasing problem known as research misconduct.
\end{abstract}

Keywords: Consequences, detection, historical overview, plagiarism types

Pharm Biomed Res 2016; 2(2): 1-8

\section{Historical overview}

The term known as "plagiarism" was first coined in English around the year 1601 by the dramatist Ben Jonson, in order to characterize someone committing theft in literary (1). Plagiarism itself has a long life history. There are countless plagiarism cases in almost every specialty in science. In astronomy, David King (a British professor of the history of science) noticed that most theories and models proposed by the famous Polish astronomer Nicolaus Copernicus in his famous book (On the Revolutions of the Celestial Spheres) were virtually adopted from Arab scientist, Ibn-Elshatir's book $(2,3)$. Writing reports and articles about plagiarism dates to late 1800 s when the 
first article written by Halsted G.B was published in "Science" in 1896 titled "complement or plagiarism"(4). From that time on, more than five hundred articles discussing plagiarism related issues have been published in "Medline" databases $(5,6,7,8)$.

\section{Terms and definitions}

Plagiarism refers to the condition when someone states that an idea or its expression belongs to him/her that actually is someone else's. Dictionaries define plagiarism as "the act of adopting someone else's work or ideas and passing them off as one's own". Moreover, it can be stated as "using another author's language, thoughts, ideas, or statements, and or portraying them as one's own authentic work but not endorsing the source $(9,10)$. The term plagiarize is taken from the Latin word plagiary to kidnap. So a plagiarist is the one committing plagiarism.

\section{Problem magnitude}

Plagiarism is of various research misconducts forms including the results fabrication, the data falsification, the data misinterpretation, special conclusions drawing and information or ideas plagiarism in a research report (11). Misconduct covers violating confidentiality and/or authorship publication in the recent years, and research has grown as a popular industry. More than 7.1 million researchers worldwide are passionately competing to get their research published in over 25,000 journals. These researchers are tense to get their work published in prestigious journals. When this pressure accompanies with insufficient time, no research skills and easily accessing information and articles available on the internet, plagiarism rate rises. In 2010, Nature
Publishing issued a report on an alarmingly growing plagiarism level. Twenty-three percent of the submitted articles have been turned down due to plagiarism (12). Plagiarism commonality differs from community to community as the rates display from 11 to $19 \%$ in medical institutions $(13,14)$. The rates go up where the concepts as intellectual property and copyrights are not fully perceived and are not accurately honored. As the intention says, plagiarism can either be unintentional or intentional. The former form of plagiarism is usually observed among students and young researchers. The latter one basically results from unawareness of the limits related to getting other sources'data and pieces of writing. Unintentional plagiarism is also due to lack of skills how to properly approve the data sources and quote the work of others (15). Intentional plagiarism is usually to intentionally copy others' work and provide it as though it is of one's own. Copying large pieces of an article deliberately intending to blind the reader to consider them as original is known as intentional plagiarism. Legally speaking, no distinction can be made between intentional and unintentional plagiarism forms; both incur legal or financial penalties and can ruin a writer's prestige (16). Thus, it is imperative for the person to appreciate how unintentional plagiarism occurs and what measures to take to be protected against it. Anyone going to submit their work has to check it in advance.

\section{Plagiarism types}

According to the nature of the plagiarized production, plagiarism can occur in many types, including plagiarism of ideas, text, designs, collusion, self-plagiarism, patch writing and many others (differences are summarized in Table 1). 
Table 1 Plagiarism Types

\begin{tabular}{|c|c|c|}
\hline Number & Type of plagiarism & Explanation \\
\hline 1 & Plagiarism of Ideas & Explanation in Text \\
\hline 2 & Plagiarism of Text & Explanation in Text \\
\hline 3 & Self- plagiarism & Explanation in Text \\
\hline 4 & Collusion & Explanation in Text \\
\hline 5 & Patch writing & Explanation in Text \\
\hline 6 & Plagiarism of Structure & $\begin{array}{c}\text { A: Paraphrasing another's words by } \\
\text { changing sentence construction or word } \\
\text { choice with citation } \\
\text { B:Paraphrasing while maintaining original } \\
\text { sentence construction with acknowledging } \\
\text { the source }\end{array}$ \\
\hline 7 & Plagiarism of Words & $\begin{array}{l}\text { A:Incorrect: Plagiarism means reproducing } \\
\text { someone else's words, ideas or findings and } \\
\text { displaying them as one's own with no } \\
\text { suitable acknowledgement. } \\
\text { B: Correct: Plagiarism is the "reproduction } \\
\text { of someone else's words, ideas or findings } \\
\text { and presenting them as one's own without } \\
\text { proper acknowledgement. }\end{array}$ \\
\hline 8 & & $\begin{array}{l}\text { 1- The Ghost Writer 2- The Photocopy } \\
\text { 3-The Potluck article 4-The Poor conceal } \\
\text { 5-The attempt of laziness } \\
\text { 6-The Self-Stealer 7-The Self-Stealer }\end{array}$ \\
\hline 9 & Sources Cited & $\begin{array}{l}\text { 1-The Forgotten Footnote 2-Misinformer } \\
\text { 3- The Too-Perfect Paraphrase } \\
\text { 4- The Resourceful Citer 5- The Perfect Crime }\end{array}$ \\
\hline & agi & $\begin{array}{l}\text { 1-Passing off as one's own pre-written } \\
\text { papers from the Internet or other sources } \\
\text { 2-Copying an essay or article from the } \\
\text { Internet, on-linesource3-Cutting and pasting } \\
\text { from more than one source to createa paper } \\
\text { without quoting or giving credit. }\end{array}$ \\
\hline 11 & Unintentional Plagiarism & $\begin{array}{l}\text { 1- Paraphrasing poorly 2- Quoting poorly 3- } \\
\text { Citing poorly }\end{array}$ \\
\hline
\end{tabular}




\section{Plagiarism of ideas}

stealing a novel idea or theorygiven anywhere. The plagiarist thenperforms research according to this idea/ theory and provides it as though it is of his own without crediting the source.

\section{Plagiarism of text}

This form is also known as "word-toword" (copy-cut-paste) writing. This occurs when a researcher takes an entire paragraph from another source and includes it in his own research writing.

\section{Self-plagiarism}

This happens when a researcher uses substantial parts of his study in two diverse publications employing similar findings or illustrations without referring to it.

\section{Collusion}

Asking someone else to write a piece of work for the plagiarist who then presents it as his own.

\section{Patch writing}

by patch writing, we mean copying pieces of another one work and altering a few of the words or the word order to look as the original one.

\section{Causes behind plagiarism}

Misbelief: a lot of researchers assume that to adopt the whole paragraphs from diverse articles and insert them in their writing is approved provided that they name the references at the end. What results will be a recent paper with some meaningful parts in "copy-cut-paste" format, defined as plagiarism. The articles with Poor time management and writing under stress, when submitted in this format are disapproved by the journals or might seem fascinating when published.
Immature writing skills: a piece of scientific writing is a language exposed to development over time. The critical tool to acquire this skill is perpetually reading literature and practicing scientific writing. By passing time, writing research articles turns as gratifying.

\section{Intentional plagiarism}

as stated before, one of the most important reasons behind plagiarism is the demanding pressure the researchers and academic staff undergo to publish their research papers: the "publish or perish" rule. Such researchers feel obliged to publish research papers in order to access funds, demonstrate their academic competency, hold on with their profession and achieve better posts in their career hierarchy $(17,18)$.

\section{Plagiarism outcomes}

The committee called "Committee on Publication Ethics" (COPE) is the prestigious one providing the guidelines for publication ethics worldwide. COPE has published many guidelines for authors and editors. In 2006, COPE published some flowcharts for the editors to make a difference between the inferior and superior plagiarism types. When superior plagiarism is detected in an issued paper after being printed, the outcomes it bears can ruin the fame of not only the plagiarist but also of the coauthors, the journal critics and editors and of the institution the plagiarist is affiliated to. Multiple sanctions forms can be taken by the editor against the plagiarist author, ranging from a letter giving the details in cases of inferior plagiarisms that mirror misunderstanding the concept, that happens in different ways ranging from formal letters sent to the plagiarist's 
institution heads, to inform them about refusing the author or their institution in case of submitting in future to renouncing and reporting to the medical councils (19). Renouncing refers to article being withdrawn after publication when it is found out that the article research is fake. Renouncing can occur for some reasons including mistaken data, wrong conclusions, not being proper to be used as a basis for wouldbe research, false claim of authorship, double publication and plagiarism. Renouncing rate has gone up to ten times more in the last few decades. When faced with renouncing, the article is not entirely deleted from the journal web site or the databases, but the title, the authors list and their affiliations are preserved plus the term "renounced" beside the title, an action that is strongly destructive for the authors' fames. To demand a certain article to be renounced is usually given to the journals' editors by the author(s) of the article, their institution or by the peer experts detecting some misconduct in the research. Having addressed and proved the wrong action, the paper will be renounced or retracted. There are many examples in which plagiarism takes a heavy toll, that is, authors and writers lose their job $(20,21)$

\section{Legal measures for plagiarism}

Among the academic settings, committing plagiarism by the students, professors or researchers is taken as academic deceit or fraud, and the ones committing this crime are subjected to academic penalties, such as dismiss. Plagiarism sanctions vary for the undergraduate and postgraduate students, covering one of the following cases: A-To redo the assignment/paper, B-To fail the assignment/paper,
C-To redo the class degree or D-To fail the degree (22).

\section{How is plagiarized writing detected?}

Before, plagiarized work used to be detected by the editors and it mainly depended on personal experience. Each author has a special writing style. The act of copying and pasting from different authors can be easily identified by professional editors and reviewers. Recently, some software-based services have been devised for plagiarism detection in scientific publications. Some of these software services are free, while others are commercial; the potentials of these software devices differ in plagiarism detection (23).

Virginia Bioinformatics Institute offers ETBLAST as a free service This service is able to detect identical matches between two articles in several databases including Medline. It is available on the website: http://etest.vbi.vt.edu/etblast3/.Turnitin plagiarism detection software is another tool. Turnitin is a popular global program supplied by I Paradigms and it is used by teachers and professors. The institutions are required to pay annual fees to access this service for their staff and students. Another famous service is iThenticate, which is also supplied by IParadigms (23). Lately, the journals which employ plagiarism-detection software check the submitted articles before their publication approval to avoid post-publication retractions (20).

These services can detect matching percentage between the submitted article and the original sources. No exact agreed-upon "percentage of match" exists in the world above which a manuscript is deemed plagiarized; however, some institutions and journals consider figure range as $20 \%$ and $30 \%$ 
based on which a manuscript can be turned down due to plagiarism $(24,25)$. These software programs are not sufficiently used to make a decision about the plagiarized work (after comparing the submitted written document and the original work). Each case has to be judged to the related context. So in order for editors to make appropriate decisions, some meaningful input is required (20).

\section{Solutions}

Supplying plagiarism-free scientific writing is a common responsibility that any medical institution has. This responsibility is on the shoulders of three key members of the institution: the students/ junior researchers, the experts/senior staff and the institution itself. Here, some recommendations are given for each group that may help to solve the ever growing problem of plagiarism:

\section{For students and junior researchers}

To avoid plagiarism, when ever no other one's idea, opinion, theory, facts, statistics, graphs, drawings or any piece of information is adopted in their own research, source credit (i.e., mentioning references) is a must. In case of including the exact words from another source in a piece of writing, these words should be put between quotation marks " " followed by crediting the source. As a scientific fact is taken from an original article, it should be written in the author's own words, not an exact copy of the paragraph from the source. This is known as "paraphrasing" and does not change the scientific facts. Even if another person's writings are paraphrasing, the source has to be credited. Using one of the plagiarismdetection services (aforementioned) is effective to distinguish the plagiarized pieces of writing not detected in the new manuscript $(25,26)$.

\section{For experts and senior researchers}

It is a demanding task in particular for new junior researchers to writing an article; they have to be supported by the senior researchers. Supervisors, tutors and the mentors require their junior researchers' assistance to draw an outline for the entire writing subject. Then the subject can be split into several small pieces. And the supervisors can agree with the students/juniors to set a deadline for each piece and discuss it with the student/junior researcher how to enrich writing the next piece of writing. Scholarly writing requires training and practice like any other skill, and particularly for junior researchers, and for senior experts, it needs patience and time (26).

\section{For institutions}

The most fundamental step to block plagiarism is to make sure that the institution students and researchers are equipped with the adequate knowledge about plagiarism, its forms, types, outcomes and how to avoid committing it. As stated, it is well understood/known that the students and researchers will perceive the issue of plagiarism thoroughly and will appreciate its seriousness better in case of being delivered in interactive workshops and seminars rather than in lectures, oral advice or warnings. Several plagiarism-detection services and software programs have been made accessible as the practical tools for both students and experts; the students are able to check their writing for pieces that may have an exact match in the previously published articles, and the 
senior staff and journals are also capable to compare the submitted articles with the plagiarized work. These services can greatly assist to lower the rate of plagiarism within the institutions. And the senior staff is required to pay attention that ahead of employing plagiarism-detection services, they should ensure that the students get the meaning behind plagiarism and how to dodge it. A software tool to detect plagiarism helps to discover the sources containing the identical text as the submitted one. Any decision to judge any work as the plagiarized one has to be made cautiously and when both the submitted paper and the suspected source are meticulously cross-checked $(26,27)$.

\section{References:}

1. Valpy F. Etymological dictionary of the Latin language: Adegi graphics LLC; 1999.

2. SalibaG. Theory and observation in Islamic astronomy the work of Ibn-Al of Damascus. J Hist Astronomy 1987: 18- 35.

3. King DA. Astronomy in the service of Islam: variorum; 1993.

4. Halsted GB. Compliment or plagiarism. Science 1896;4:877-8.

5. Masic I. Plagiarism in scientific publishing. Acta Inform Med 2012; 20 : 208-13.

6. Meerloo JA. Plagiarism and identification. Arch Gen Psychiatry 1964; 11: 421- 424 .

7. Nathan MH. Variations of plagiarism. AJR Am J Roentgenol 1994; 163: 727 -30 .

8. Palca J./ Plagiarism dispute. Clinical researchers at odds. Nature 1989;338: 192.

9. Oxford English dictionary. 11 ed 2008.

10. Dictionary M-W. Marriam-Webster dictionarsry; 2014.

11. Guraya S, London N, Guraya S. Ethics in medical research. J MicroscUltrastruct 2014; 2: 121-26.

12. Maurer HA, KappeF, Zaka B, Plagiarism - a survey, J. Universal Comput. Sci (JUSC) 2006;12:1050-84.

13. Bazdaric K, Bilic-Zulle L, Brumini G, Petrovecki M. Prevalence of plagiarism

\section{Conclusion}

Plagiarism is the most prevalent issue in research writing. And the best strategy to evade this problem getting aggravated is to build up the knowledge on it. To hold workshops and make plagiarism-detection software available in the institutions can be required tools to guard against plagiarism. Besides, trust and honesty inextricably intertwined with the ethics of scientific research; what violates these values is plagiarism that paves the ground for distrust and consequently, averts scientific progress. in recent submissions to the CroatianMedical Journal. Sci Eng Ethics 2012; 18: 223-39.

14. Bilic-Zulle L, Frkovic V, Turk T, Azman J, PetroveckiM. Prevalence of plagiarism among medical students. Croat Med J 2005; 46:126-131.

15. Das N, Panjabi M. Plagiarism: why is it such a big issue for medical writers? Perspect Clin Res 2011; 2:67-71.

16. Freckelton I. Plagiarism in law and medicine: challenges for scholarship, academia, ublishers and regulators. J Law Med2010; 17: 645-59.

17. Ambrose CT. Plagiarism of ideas. Benjamin Rush and Charles Caldwelle a student-mentor dispute. Pharos Alpha Omega Alpha-Honor Med Soc Alpha Omega Alpha 2014; 77:14-23.

18. Triggle CR, Triggle DJ. What is the future of peer review? Why is there fraud in science? Is plagiarism out of control? Why do scientists do bad things? Is it all a case of: "all that is ecessary for the triumph of evil is that good men do nothing" Vasc Health Risk Manag 2007; 3:39-53.

19. Reyes BH. Plagiarism in scientific publications. Rev Medical Chile 2009; 137:7-9.

20. Andreescu L. Self-plagiarism in academic publishing: the anatomy of a misnomer. Sci Eng Ethics 2013; 19:775-97 
21. London UE. Guidance for students on collusion. University of East London 2010: 7:86-7.

22. $\mathrm{Li} \mathrm{Y}$. Text-based plagiarism in scientific writing: what Chinese supervisors think about copying and how to reduce it in students' writing. SciEng Ethics 2013;19:569-83.

23. Flow charts -committee on publication ethics: COPE [cited 2014 18th October, 2014].

24. P.M. Scanlon, DR. Neumann, Internet plagiarism among college students, J. College Student Develop 2002;43:37485 .
25. Rawat S, Meena S. Publish or perish: where are we heading? J Res Med Scioff J Isfahan Univ Med Sci 2014; 19:87-89.

26. Neill US. Publish or perish, but at what cost? J Clin Investig 2008; 118:2368.

27. Jenny G, Wlodek J K, Anette P.Teaching International Students How to Avoid plagiarism Librarians and Faculty in Collaboration the Journal of Academic Librarianship.2014; 70: 4137.

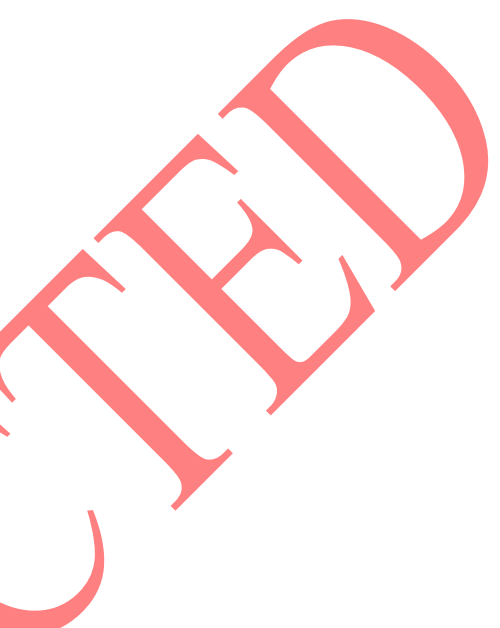

